\title{
Ongoing outbreak of invasive listeriosis due to serotype 1/2a Listeria monocytogenes, Ancona province, Italy, January 2015 to February 2016
}

E Marini ${ }^{1}$, G Magi $^{1}$, C Vincenzi $^{1}$, E Manso $^{2}$, B Facinelli ${ }^{1}$

1. Unit of Microbiology, Department of Biomedical Sciences and Public Health, Polytechnic University of Marche Medical School, Ancona, Italy

2. Clinical Microbiology Laboratory, Torrette Regional Hospital, Ancona, Italy

Correspondence: Bruna Facinelli (b.facinelli@univpm.it)

Citation style for this article:

Marini E, Magi G, Vincenzi C, Manso E, Facinelli B. Ongoing outbreak of invasive listeriosis due to serotype $1 / 2$ a Listeria monocytogenes, Ancona province, Italy, January 2015 to February 2016. Euro Surveill. 2016;21(17):pii=30217. DOI: http://dx.doi.org/10.2807/1560-7917.ES.2016.21.17.30217

Article submitted on 05 April 2016 / accepted on 28 April 2016 / published on 28 April 2016

In the first seven weeks of 2016 , five serotype $1 / 2 a$ Listeria monocytogenes isolates were collected from patients with invasive listeriosis in Ancona province in Italy. These strains and six $1 / 2 a$ isolates identified in 2015 in the same area were typed by ERIC-PCR and PFGE. A clonal relationship, documented between the two sets of isolates, suggested a listeriosis outbreak in Ancona that started most probably in 2015 . Investigation into the source of infection is still ongoing.

In the first seven weeks of 2016 , six cases of invasive listeriosis were recorded in Ancona province, Italy. Five strains of Listeria monocytogenes serotype $1 / 2 \mathrm{a}$ were isolated and typed by enterobacterial repetitive intergenic consensus (ERIC)-PCR and PFGE, indicating clonality. In addition, seven serotype 1/2a L. monocytogenes strains from cases of invasive listeriosis recorded in the same area in 2015 were also typed and showed relatedness. Here we provide details of the ongoing outbreak.

\section{Outbreak description}

From 4 January to 15 February 2016, six L. monocytogenes strains (3 from blood, 3 from cerebrospinal fluid (CSF)) were isolated from six patients diagnosed with invasive listeriosis at the Clinical Microbiology Laboratory of Ancona Regional Hospital (eastern Italy) of Area Vasta $2\left(\mathrm{AV}_{2}\right)$ which encompasses Ancona, Fabriano, Senigallia, and Jesi. Patients had been admitted to four different departments: emergency room (ER) $(n=2)$, oncology $(n=2)$, infectious diseases $(n=1)$, and intensive care unit (ICU) $(n=1)$. Four of the six patients were women and the most common risk factors/underlying conditions were: age $(n=5 ;>71$ years), cancer $(n=2)$, and diabetes $(n=1)$. Clinical manifestations included septicaemia $(n=3)$, meningitis $(n=2)$ and meningoencephalitis $(n=1)$.
In addition to the cases detected in 2016, eight $L$. monocytogenes strains ( 5 from blood and 3 from CSF) had been isolated in $\mathrm{AV}_{2}$ (from 7 cases) and nearby Ascoli Piceno (from 1 case) in 2015 (Figure 1); clinical samples came from six hospital departments: $\operatorname{ER~}(n=1)$, general medicine $(n=3)$, nephrology $(n=1)$, vascular surgery $(n=1)$, infectious diseases $(n=1)$, and ICU $(n=1)$. Five patients were men and the mean patient age was 73.6 years (range: $55-84$; median: 75 ); a 77 year-old man died.

The 2015 and 2016 isolates were identified as L. monocytogenes by Gram staining and the Vitek MS system (bioMérieux Italia SpA, Firenze, Italy). Susceptibility to ampicillin, meropenem, erythromycin, and sulphamethoxazole-trimethoprim was tested by the E-Test (Liofilchem, Teramo, Italy) according to the European Committee on Antimicrobial Susceptibility Testing (EUCAST) guidelines [1]. All strains were susceptible to all the antibiotics tested.

\section{Molecular typing}

In order to identify relatedness, the 2015 and 2016 L. monocytogenes isolates were sent to our laboratory (Unit of Microbiology, Department of Biomedical Sciences and Public Health, Polytechnic University of Marche, Ancona) for molecular typing. Multiplex PCR serotyping [2] assigned five 2016 isolates and seven 2015 isolates to serotype $1 / 2 \mathrm{a}$; the remaining isolates were serotype $4 \mathrm{~b}$ (2016) and serotype $1 / 2 c$ (2015).

Genetic relatedness was explored by ERIC-PCR [3] and by PFGE after Apal digestion of total DNA [4]. ERIC pattern similarity was determined on the basis of the Dice similarity coefficient; the matrix thus generated was subjected to clustering using TREECON software (Bioinformatics and Evolutionary Genomics, Gent, Belgium). The 1/2a 2015 and 2016 isolates shared a 


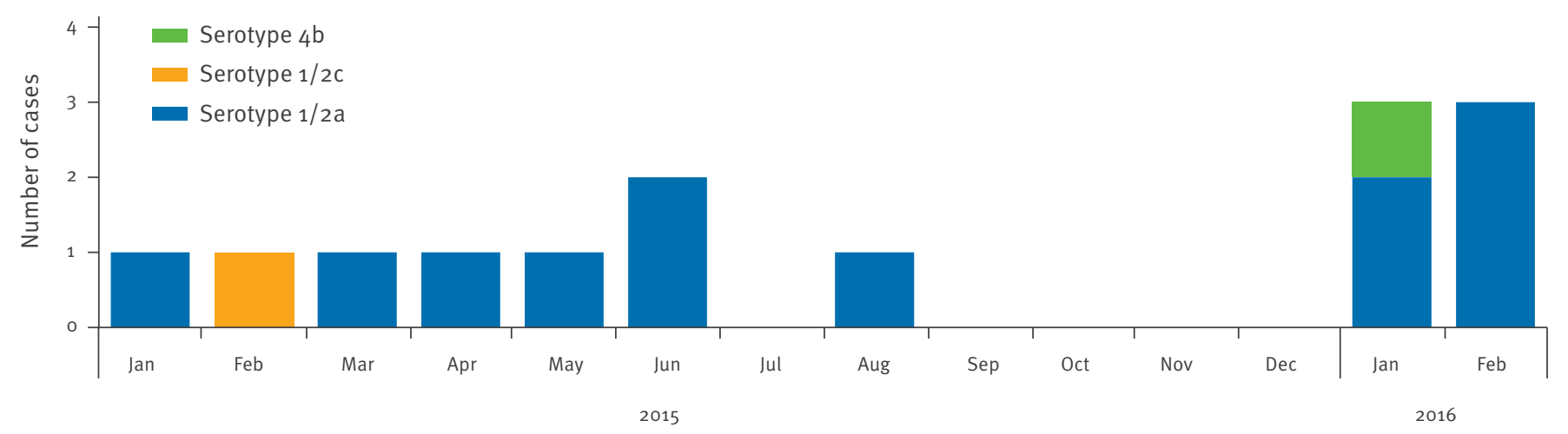

Date of isolation

\section{FIGURE 2}

Enterobacterial repetitive intergenic consensus (ERIC)-PCR-based dendrogram showing the similarity index among the Listeria monocytogenes isolates, Ancona province, January 2015 to February $2016(\mathrm{n}=14)$

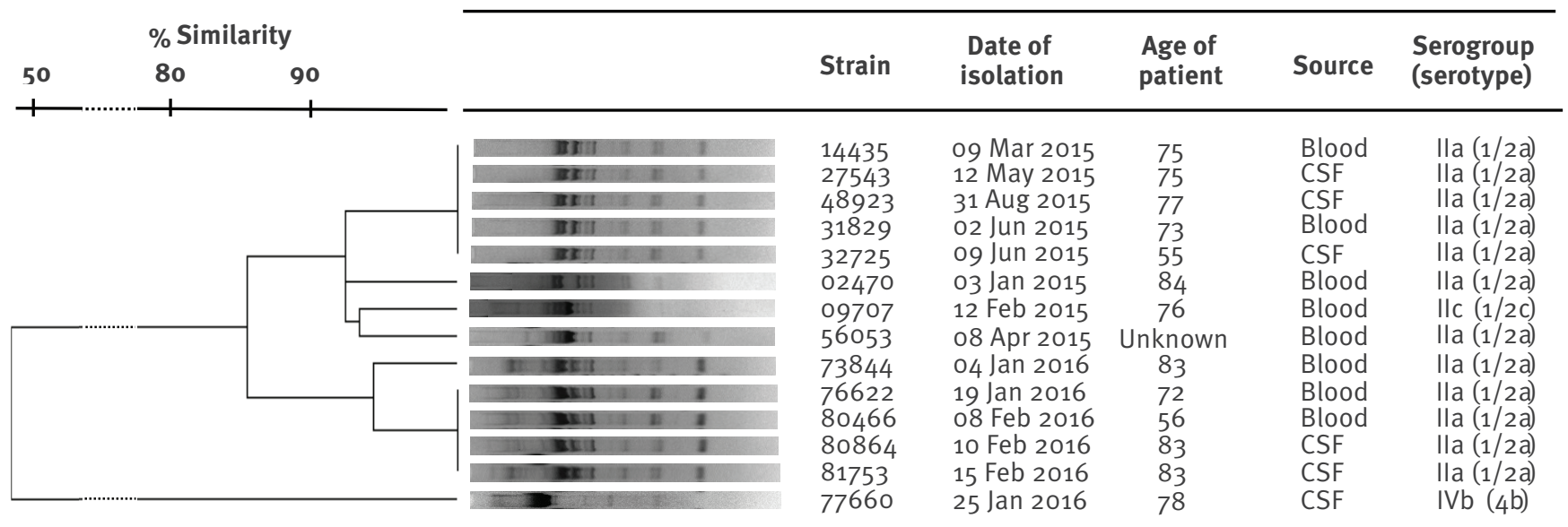

CSF: cerebrospinal fluid.

The scale at the top indicates the degree of genetic relatedness.

five-band pattern ranging from 1,500 to $900 \mathrm{bp}$ (Figure 2).

Moreover, four of five serotype $1 / 2 \mathrm{a} 2016$ isolates (76622, 80466, 80864, 81753) displayed identical ERIC PCR profiles; the remaining isolate (73844) differed by one band ( $>90 \%$ similarity index). The profile of the serotype $4 \mathrm{~b}$ strain (77660) was completely different ( $(50 \%$ similarity index). All 1/2a 2015 isolates showed a high degree of similarity ( $>85 \%$ ) with respect to the 1/2a 2016 isolates. Notably, the profile of the single serotype $1 / 2 \mathrm{C}$ isolate (09707) was closely related to that of the $1 / 2 a$ isolates.

PFGE analysis confirmed ERIC PCR results, except for two 1/2a isolates, i.e. strain 56053 (Ascoli Piceno) and strain 02470 (the first 2015 isolate) (data not shown). The DNA of serotype 1/2C strain 09707 was not digested by Apal.

\section{Background}

L. monocytogenes is widely distributed in the environment and is frequently isolated from a variety of sources, including soil, vegetation, food of animal origin such as meat and dairy products, silage, fecal material, sewage, and water [5]. Listeriosis is most often transmitted through food and primarily affects older adults, pregnant women, newborns, and adults with weakened immune systems [5]. Serotyping is a universally accepted typing method for L. monocytogenes, with more than 14 serotypes being recognised according to variation in somatic $(\mathrm{O})$ and flagellar $(\mathrm{H})$ antigens [6]. Multiplex PCR serotyping is a practical alternative to slide agglutination serotyping, since it differentiates among the five major serogroups, each of which 
includes multiple serotypes: serogroup IVb (serotypes $4 \mathrm{~b}, 4 \mathrm{~d}$ and $4 \mathrm{e}$ ), serogroup Ila (serotypes $1 / 2 \mathrm{a}$ and $3 \mathrm{a}$ ), serogroup IIb (serotypes $1 / 2 \mathrm{~b}, 3 \mathrm{~b}$ and 7 ), serogroup IIC (serotypes $1 / 2 \mathrm{C}$ and $3 \mathrm{C}$ ), and serogroup IVa (serotypes $4 \mathrm{a}$ and $4 \mathrm{C}$ ). By use of suitably designed primer pairs, the four major serotypes $1 / 2 a, 1 / 2 b, 1 / 2 c$, and $4 b$ produce four distinct PCR profiles [2]. PFGE is considered as the gold standard molecular typing approach for $L$. monocytogenes, owing to its high reproducibility and discrimination ability [4]. ERIC PCR is a relatively simple, cost-effective, and discriminatory typing method based on ERIC sequences, 124 to 127 base-long elements consisting of highly conserved central inverted repeats found in the extragenic regions of the bacterial genome [3].

\section{Discussion and conclusion}

The incidence of listeriosis has been rising since the early 2000 s in several European countries, mainly in immunocompromised patients older than 65 years [7-9]. In particular, a statistically significant increase was reported in Austria, Denmark, Hungary, Italy, France, Spain, and Sweden from 2005 to 2009 [10]. In the past 30 years, outbreaks of listeriosis have been mostly linked to serotype $1 / 2 a$ and $4 b$ clones [8]. A shift to serotype $1 / 2 a$ has been observed in Europe and North America in the last decade [8]. In Italy, surveillance of invasive listeriosis has found an increase in serotype $1 / 2$ a isolates over the same period, mainly in the central and northern regions (about $80 \%$ of cases) [10-14].

Listeriosis is an infection of great concern to public health due its clinical severity and high case fatality rate, despite its low incidence compared with other foodborne diseases such as salmonellosis or campylobacteriosis. The present data suggest an ongoing outbreak of listeriosis due to serotype $1 / 2$ a L. monocytogenes in AV2 that most probably started in 2015 , since the strain was already present in the area in 2015. As in other European countries, most cases were associated with an underlying condition and involved elderly people $[8,9]$. Local authorities are working with the Italian national public health institute (the Istituto Superiore di Sanità, Rome) and the regional Istituto Zooprofilattico Umbria and Marche to identify the sources of food contamination. A recent press release [15] points out that there are findings which suggest contamination of a pork product as a possible vehicle of infection for at least one human case. At present, however, no clear link can be established between the contaminated pork product and the infections. Investigation into the source of infection in $\mathrm{AV}_{2}$ is still in progress.

\section{Conflict of interest}

None declared.
Authors' contributions

E. Marini, G. Magi and B. Facinelli designed and developed the experimental design. E. Manso and C. Vincenzi collected bacterial strains and epidemiological data; E. Marini and G. Magi performed experiments; B. Facinelli, E. Marini and G. Magi performed data analysis and wrote the manuscript. All authors reviewed and approved the study.

\section{References}

1. European Committee on Antimicrobial Susceptibility Testing (EUCAST). Breakpoint tables for interpretation of MICs and zone diameters. Version 6.0, valid from 2016-01-01. Växjö: EUCAST. [Accessed 15 Apr 2016]. Available from: http:// www.eucast.org/fileadmin/src/media/PDFs/EUCAST_files/ Breakpoint_tables/v_6.o_Breakpoint_table.pdf

2. Doumith M, Buchrieser C, Glaser P, Jacquet C, Martin P. Differentiation of the major Listeria monocytogenes serovars by multiplex PCR.J Clin Microbiol. 2004;42(8):3819-22. DOI: 10.1128/JCM.42.8.3819-3822.2004 PMID: 15297538

3. Jersek B, Gilot P, Gubina M, Klun N, Mehle J, Tcherneva E, et al. Typing of Listeria monocytogenes strains by repetitive element sequence-based PCR. J Clin Microbiol. 1999;37(1):103-9.PMID: 9854072

4. Graves LM, Swaminathan B. PulseNet standardized protocol for subtyping Listeria monocytogenes by macrorestriction and pulsed-field gel electrophoresis.Int J Food Microbiol. 2001;65(1-2):55-62. DOI: 10.1016/S0168-1605(00)00501-8 PMID: 11322701

5. Freitag NE, Port GC, Miner MD. Listeria monocytogenes - from saprophyte to intracellular pathogen. Nat Rev Microbiol. 2009;7(9):623-8. DOI: 10.1038/nrmicr02171 PMID: 19648949

6. Graves LM, Swaminathan B, Hunter S. Subtyping Listeria monocytogenes. In: Ryser ET, Marth EH, editors. Listeria, listeriosis, and food safety, New York: Marcel Dekker Inc; 1999, p. 279-298.

7. European Food Safety Authority (EFSA), European Centre for Disease Prevention and Control (ECDC). The European Union summary report on trends and sources of zoonoses, zoonotic agents and food-borne outbreaks in 2012.EFSA Journal.2014;12(2):3547.

8. Lomonaco S, Nucera D, Filipello V. The evolution and epidemiology of Listeria monocytogenes in Europe and the United States.Infect Genet Evol. 2015;35:172-83. DOI: 10.1016/j.meegid.2015.08.008 PMID: 26254574

9. Goulet V, Hedberg C, Le Monnier A, de Valk H. Increasing incidence of listeriosis in France and other European countries.Emerg Infect Dis. 2008;14(5):734-40. DOI: 10.3201/ eid1405.071395 PMID: 18439354

10. Pontello M, Guaita A, Sala G, Cipolla M, Gattuso A, Sonnessa $M$, et al. Listeria monocytogenes serotypes in human infections (Italy, 2000-2010). Ann Ist Super Sanita. 2012;48(2):146-50. DOI: 10.4415/ANN_12_02_07 PMID: 22751557

11. Gianfranceschi MV, Gattuso A, D'Ottavio MC, Fokas S, Aureli P. Results of a 12-month long enhanced surveillance of listeriosis in Italy.Euro Surveill. 2007;12(11):E7-8.PMID: 18005656

12. Mammina C, Aleo A, Romani C, Pellissier N, Nicoletti $P$, Pecile $P$, et al. Characterization of Listeria monocytogenes isolates from human listeriosis cases in Italy. J Clin Microbiol. 2009;47(9):2925-30. DOI: 10.1128/JCM.00102-09 PMID: 19605584

13. Mammina C, Parisi A, Guaita A, Aleo A, Bonura C, Nastasi $A$, et al. Enhanced surveillance of invasive listeriosis in the Lombardy region, Italy, in the years 2006-2010 reveals major clones and an increase in serotype $1 / 2$ a. BMC Infect Dis. 2013;13(1):152. DOI: 10.1186/1471-2334-13-152 PMID: 23530941

14. de Francesco MA, Corbellini S, Piccinelli G, Benini A, Ravizzola $\mathrm{G}$, Gargiulo F, et al. A cluster of invasive listeriosis in Brescia, Italy. Infection. 2015;43(3):379-82. DOI: $10.1007 /$ S15010-0150736-3 PMID: 25687587

15. Regione Marche. Aggiornamento sull'aumento di casi di listeriosi umana nelle Marche. [Increase in the number of human cases of listeriosis in Marche]. Press release. [Accessed 28 Apr 2016]. Italian. Available from: http://www.regione. marche.it/Home/ComunicatiStampa.aspx?id=25373 
License and copyright

This is an open-access article distributed under the terms of the Creative Commons Attribution (CC BY 4.0) Licence. You may share and adapt the material, but must give appropriate credit to the source, provide a link to the licence, and indicate if changes were made.

This article is copyright of the authors, 2016. 